\title{
Curing of Polyfunctional Spiro Ortho Esters by Carbon Black
}

\author{
Norio TsuboKawa, Shingo OHShima, Yasuo Sone, \\ and Takeshi ENDO* \\ Department of Applied Chemistry, Faculty of Engineering, Niigata University, \\ Ikarashi 2-8050, Niigata 950-21, Japan \\ * Research Laboratory of Resources Utilization, Tokyo Institute of Technology, \\ Nagatsuta, Midori-ku, Yokohama 227, Japan
}

(Received June 14, 1986)

\begin{abstract}
The crosslinking reaction of polyfunctional spiro ortho esters (SOE), i.e., polymers (resins) that bear SOE structure, by carbon black was investigated. The copolymers of 2methylene-1,4,6-trioxaspiro[4.6]undecane with vinyl monomers were crosslinked in solution upon heating $\left(150^{\circ} \mathrm{C}\right)$ together with carbon black to give gels. Furthermore, carbon black was found to be able to cure the SOE resins, which are prepared from epoxy resins and $\varepsilon$-caprolactone, at 120 $180^{\circ} \mathrm{C}$ in bulk. The curing ability of carbon black was enhanced with an increase in the content of carboxyl and phenolic hydroxyl groups on carbon black. By the neutralization of carboxyl group on carbon black, the curing ability of the carbon black decreased remarkably. Carbon black lost the curing ability upon the blocking of both carboxyl and phenolic hydroxyl group by the treatment with diazomethane. Based on these results, it was concluded that both carboxyl and phenolic hydroxyl groups on carbon black play an important role in the curing of polyfunctional SOE resins.

KEY WORDS Carbon Black / Polyfunctional Spiro Ortho Esters / Spiro

Ortho Ester Resin / Curing Agents / Crosslinking / Gel Fraction /

Functional Groups on Carbon Black /
\end{abstract}

In the preceding paper, we reported that the ring-opening transfer polymerization of spiro ortho esters (SOE), such as 2-substituted 1,4,6-trioxaspiro[4.6]undecane, can be initiated by carbon black to give polyether ester. ${ }^{1}$ In the course of the polymerization, the polymer formed was grafted onto a carbon black surface. ${ }^{1}$ The initiating sites of the polymerization were considered to be carboxyl groups on carbon black. ${ }^{1}$

It has been reported that copolymers of unsaturated SOE with vinyl monomers and polymers that bear the SOE structure, namely SOE resins, are crosslinked with no shrinkage by cationic additives such as carboxylic acid anhydride, polycarboxylic acid, and boron trifluoride etherate. ${ }^{2}$ On the other hand, we demonstrated that carbon black acts as polycarboxylic acid and has an ability to cure epoxy resins. ${ }^{3}$

In the present paper, we wish to report the crosslinking of copolymers (1 and 2 ) bearing the SOE structure and SOE resins $(\mathbf{3}, \mathbf{4}$, and 5), which are prepared from epoxy resin and $\varepsilon$-caprolactone as shown below, by carbon black. Furthermore, the curing mechanism by carbon black is discussed.

\section{EXPERIMENTAL}

\section{Materials}

Carbon blacks used were both furnace black and color channel black. Furnace black Philblack O (Philips Petroleum Co.) was extracted with benzene before use to remove resinous substances present on the surface. Channel blacks FW 200 (Degussa A.G.), Carbolac 1 (Cabot Corp.) and Neospectra II (Columbian 


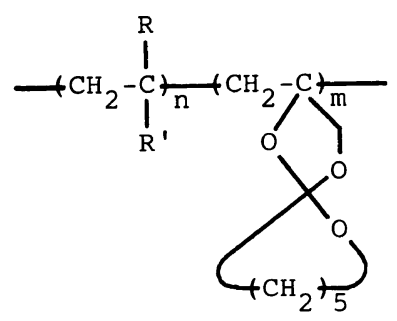

$$
\begin{aligned}
& \mathrm{R}=\mathrm{H}, \mathrm{R}^{\prime}=\mathrm{CN}(\mathbf{1}) \\
& \mathrm{R}=\mathrm{CH}_{3}, \mathrm{R}^{\prime}=\mathrm{COOCH}_{3}(\mathbf{2})
\end{aligned}
$$
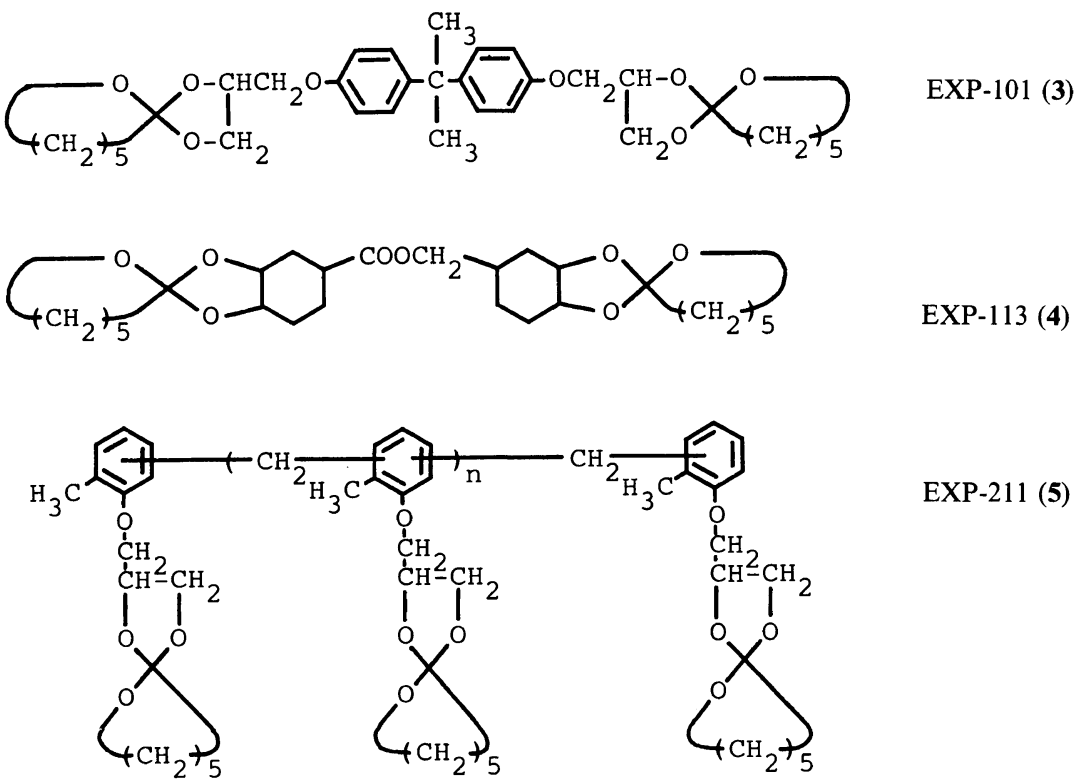

EXP-211 (5)

Carbon Co.) were used without extraction because channel blacks contain no resinous substances. The BET specific surface area, $\mathrm{pH}$, and the content of carboxyl $(\mathrm{COOH})$, phenolic hydroxyl $(\mathrm{OH})$, and quinonic oxygen $(\mathrm{C}=\mathrm{O})$ groups on these carbon blacks are summarized in Table I.

Acrylonitrile, methyl methacrylate, and nitrobenzene used as solvent were purified by usual methods.

\section{Preparation of Copolymers $\mathbf{1}$ and $\mathbf{2}$}

Copolymers 1, poly(2-methylene-1,4,6trioxaspiro[4.6] undecane-co-acrylonitrile), and 2, poly(2-methylene-1,4,6-trioxaspiro[4.6]undecane- $c o$-methyl methacrylate), were prepared by the method of literature. ${ }^{4} \mathrm{~A}$ typical example is as follows. In a sealed tube,

\begin{tabular}{|c|c|c|c|c|}
\hline \multirow{3}{*}{ Carbon black } & $\begin{array}{c}\text { BET } \\
\text { specific } \\
\text { surface }\end{array}$ & $\mathrm{pH}$ & $\mathrm{OH}$ & $\mathrm{C}=\mathrm{O}$ \\
\hline & area & \multicolumn{3}{|c|}{$\mathrm{pH} \overline{\text { meq g }^{-1}} \overline{\text { meq g }^{-1}} \overline{\text { meqg }^{-1}}$} \\
\hline & $\mathrm{m}^{2} \mathrm{~g}^{-1}$ & & & \\
\hline FW $200^{\mathrm{a}}$ & 460 & 0.61 & 0.10 & 1.42 \\
\hline Carbolac $1^{\mathrm{a}}$ & 839.2 & 0.54 & 0.16 & 1.14 \\
\hline Neospectra $I^{\mathrm{a}}$ & 906 & 0.40 & 0.24 & 0.92 \\
\hline Philblack $\mathrm{O}^{\mathrm{b}}$ & 79.6 & 8.7 & 0.02 & 0.18 \\
\hline \multicolumn{5}{|l|}{$\begin{array}{l}\text { a Channel black. } \\
\text { b Furnace black. }\end{array}$} \\
\hline \multicolumn{5}{|c|}{$\begin{array}{l}0.61 \mathrm{~mol} \text { of acrylonitrile or methyl methac- } \\
\text { rylate and } 0.61 \mathrm{~mol} \text { of } 2 \text {-methylene- } 1,4,6- \\
\text { trioxaspiro[4.6]undecane } \mathrm{e}^{5} \text { were copolymerized } \\
\text { using } 0.3 \mathrm{~mol} \% \text { of } 2,2^{\prime} \text {-azobisisobutyroni- }\end{array}$} \\
\hline
\end{tabular}

Table I. Properties of carbon black 
Table II. Properties of SOE resins

\begin{tabular}{|c|c|c|c|}
\hline \multirow{2}{*}{ SOE resin } & \multirow{2}{*}{ Appearance } & $\mathrm{mp}$ & $\begin{array}{l}\text { Viscosity } \\
\text { at } 50^{\circ} \mathrm{C}\end{array}$ \\
\hline & & C & $\mathrm{Pas}$ \\
\hline 3 EXP-101 & Pale yellow liquid & - & $150-200$ \\
\hline 4 EXP-113 & Pale yellow solid & $60-80$ & - \\
\hline 5 EXP-211 & Pale yellow solid & $70-90$ & - \\
\hline
\end{tabular}

trile as initiator at $80^{\circ} \mathrm{C}$ for $5 \mathrm{~h}$. The content of SOE moiety in $\mathbf{1}$ and $\mathbf{2}$ was determined to be $43 \mathrm{~mol} \%$ and $3 \mathrm{~mol} \%$, respectively, by elementary analysis.

\section{Polyfunctional SOE Resins (3, 4, and 5)}

Polyfunctional SOE resins, 3, 4, and 5, were obtained from Toagosei Chemical Ind. Co., Ltd. under the designations EXP-101, EXP211, and EXP-113, respectively. The properties of these resins are shown in Table II. ${ }^{2,6}$ These resins were dried in vacuo at $60^{\circ} \mathrm{C}$, and pulverized in a dry atmosphere before use.

\section{Crosslinking of Copolymers 1 and $\mathbf{2}$}

To a solution of $2.0 \mathrm{~g}$ of 1 or 2 in $10.0 \mathrm{ml}$ of nitrobenzene, $0.30 \mathrm{~g}$ of $\mathrm{FW} 200$ was added. The mixture was stirred at $150^{\circ} \mathrm{C}$ with a magnetic stirrer under dry nitrogen. After the reaction, the product was filtered and extracted with tetrahydrofuran using a Soxhlet apparatus and then the gel fraction was calculated by the following equation.

Gel fraction $(\%)$

$$
=\frac{\begin{array}{c}
\text { Weight of product } \\
\text { after extraction }(\mathrm{g})
\end{array}-\begin{array}{l}
\text { Carbon black } \\
\text { contained }(\mathrm{g})
\end{array}}{\begin{array}{c}
\text { Weight of product } \\
\text { before extraction }(\mathrm{g})
\end{array}-\begin{array}{l}
\text { Carbon black } \\
\text { contained }(\mathrm{g})
\end{array}} \times 100
$$

\section{Curing of 3, 4, and 5 by Carbon Black}

In a $50 \mathrm{ml}$ beaker, $0.50 \mathrm{~g}$ of FW 200 was mixed with $1.0 \mathrm{~g}$ of powdered SOE resin with a spatula at room temperature and then at about $80^{\circ} \mathrm{C}$; on a hot plate. Subsequently, the mixture was heated at a given temperature in a electric oven. After a definite time, the product was extracted with tetrahydrofuran, which is a good solvent for SOE resins, using a Soxhlet apparatus. The gel fraction was calculated by the equation shown above.

\section{Treatment of Carbon Black}

Treatment of carbon black with potassium hydroxide, ${ }^{7}$ diazomethane, ${ }^{8}$ and nitric acid ${ }^{1,9}$ was carried out as previously repoted. The procedure of the treatment with potassium bicarbonate was analogous to that with potassium hydroxide.

\section{RESULTS AND DISCUSSION}

\section{Crosslinking of Copolymers $\mathbf{1}$ and $\mathbf{2}$ by Car- bon Black}

It has been reported that the copolymers 1 and 2 can be crosslinked by cationic catalyst such as boron trifluoride etherate and polycarboxylic acid due to the cationic ringopening transfer polymerization of SOE moieties. ${ }^{2}$ On the other hand, carboxyl group on carbon black was capable of initiating the cationic ring-opening transfer polymerization of SOE derivatives. ${ }^{1}$

Therefore, it is expected that carbon black has an ability to crosslink the copolymers 1 and 2. Table III shows the result of the crosslinking reaction of $\mathbf{1}$ and $\mathbf{2}$ by carbon black in nitrobenzene at $150^{\circ} \mathrm{C}$.

As shown in Table III, the crosslinking reaction of these copolymers occurred upon heating together with carbon black FW 200 to give gels. On the contrary, in the absence of carbon black, the reaction was not observed and these copolymers were recovered unchanged.

Accordingly, it became apparent that FW 200 has an ability to crosslink the copolymers containing SOE moieties.

\section{Curing of SOE Resins 3 by Carbon Black}

SOE resins such as $\mathbf{3 , 4}$, and 5 are cured with no shrinkage by boron trifluoride etherate, 
Table III. Crosslinking of copolymers 1 and 2 by FW 200

\begin{tabular}{|c|c|c|c|}
\hline \multirow{2}{*}{ Copolymer } & SOE moiety & Time & Gel fraction ${ }^{a}$ \\
\hline & $\mathrm{mol} \%$ & $\mathrm{~h}$ & $\%$ \\
\hline $\mathbf{1}$ & 43 & 24 & 72.1 \\
\hline 2 & 3 & 48 & 86.8 \\
\hline
\end{tabular}

a FW 200, 0.30g; copolymer, 2.0 g; nitrobenzene, $10.0 \mathrm{ml} ; 150^{\circ} \mathrm{C}$.

carboxylic acid anhydride, polycarboxylic acid, and phenol resin. ${ }^{2}$ Therefore, it is expected that carbon black has an ability to crosslink SOE resins.

A mixture of $1.0 \mathrm{~g}$ of 3 and various amounts of carbon black FW 200 was heated at 150 ${ }^{\circ} \mathrm{C}$. Upon heating, 3 was crosslinked and a hard mass containing carbon black was obtained. Figure 1 shows the relationship between the gel fraction of the product and heating time as a function of the amount of carbon black added.

As shown in Figure 1, in the absence of carbon black the crosslinking of $3 \mathrm{did}$ not occur at all. However, in the presence of carbon black, the curing reaction of 3 proceeded. Furthermore, the rate of the reaction of carbon black with 3 increased with an increase in the amount of carbon black used.

Based on the above results, it is concluded that FW 200 acts as an effective curing agent for 3 .

\section{Effect of Temperature on the Curing of $\mathbf{3}$}

By use of $1.0 \mathrm{~g}$ of 3 and $0.5 \mathrm{~g}$ of FW 200 as a curing agent, the curing of 3 was carried out at 120,150 , and $180^{\circ} \mathrm{C}$. The results are shown in Figure 2.

Figure 2 clearly shows that the rate of the reaction increased with a rise in reaction temperature. The curing reaction at $180^{\circ} \mathrm{C}$ was extremely fast and the gel fraction went up to $100 \%$ after $1 \mathrm{~h}$, while the gel fraction at $120^{\circ} \mathrm{C}$ was about $50 \%$ even if the mixture of 3 and FW 200 was heated for $20 \mathrm{~h}$.

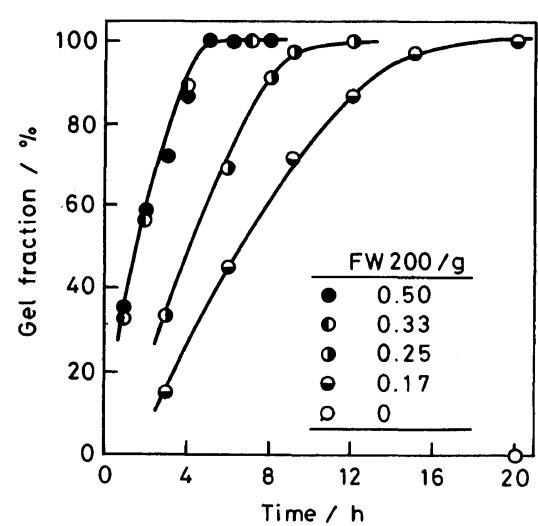

Figure 1. Effect of the amount of FW 200 on the curing of $3.3,1.0 \mathrm{~g} ; 150^{\circ} \mathrm{C}$.

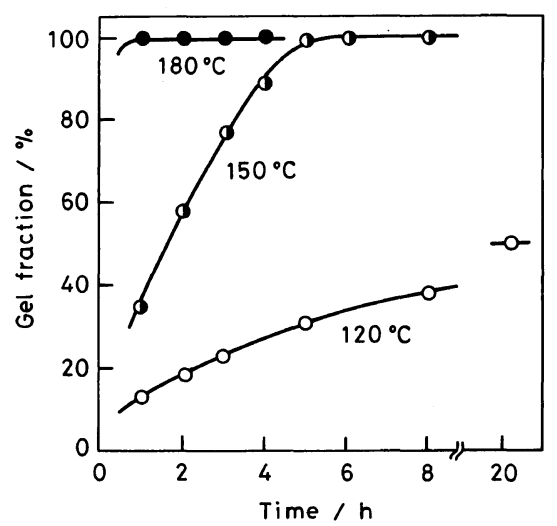

Figure 2. Effect of temperature on the curing of 3 by FW 200. FW 200, 0.50 g; 3, 1.0 g.

When dodecenyl succinic anhydride (DSA) was used as the curing agent, heating at 120 ${ }^{\circ} \mathrm{C}$ for $3 \mathrm{~h}$ and then at $180^{\circ} \mathrm{C}$ for $2 \mathrm{~h}$ was required for the curing of $3 .^{2}$ Therefore, it became apparent that the curing ability of FW 200 is superior to that of DSA.

\section{Curing of $\mathbf{4}$ and $\mathbf{5}$ by Carbon Black}

The results of the curing reaction of 4 and 5 by FW 200 as a curing agent are shown in Figures 3 and 4, respectively.

As shown in Figure 3, the gel fraction at $180^{\circ} \mathrm{C}$ went up to $100 \%$ after $8 \mathrm{~h}$. The results indicate that FW 200 also acts as curing agent for 4 , because no reaction occurred at all at $180^{\circ} \mathrm{C}$ in the absence of carbon black. 


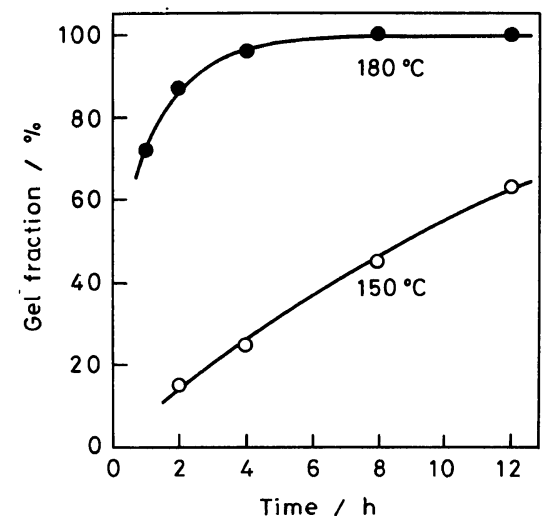

Figure 3. Curing of 4 by FW 200. FW 200, $0.50 \mathrm{~g} ; \mathbf{4}$, $1.0 \mathrm{~g}$.

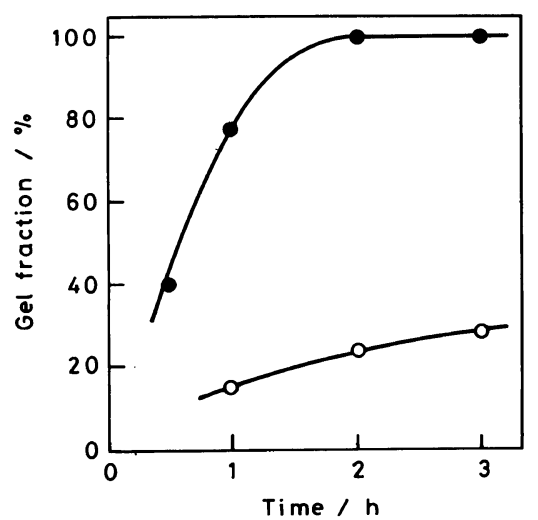

Figure 4. Curing of 5 by $\mathrm{FW} 200$ at $150^{\circ} \mathrm{C}$. FW 200, $0.20 \mathrm{~g} ; 5,1.0 \mathrm{~g}$. ( $\bigcirc)$ in the presence of FW 200; $(\bigcirc)$ in the absence of carbon black.

In the case of the curing of $\mathbf{5}$, the reaction proceeded even in the absence of carbon black. The gel fraction in the absence of carbon black, however, were much smaller than that in the presence of carbon black. Furthermore, the rate of the curing of $\mathbf{5}$ was found to be larger than those of $\mathbf{3}$ and $\mathbf{4}$.

Accordingly, it is concluded that SOE resins, 3, 4, and 5 , can be cured by carbon black FW 200.

\section{Functional Groups on Carbon Black Respon-} sible for the Curing

In the preceding paper, we pointed out that functional groups on carbon black re-
Table IV. Curing of 3 by various kinds of carbon black

\begin{tabular}{|c|c|c|c|}
\hline \multirow{2}{*}{ Carbon black } & $\mathrm{COOH}$ & $\mathrm{OH}$ & Gel fraction ${ }^{\mathrm{a}}$ \\
\hline & meq $g^{-1}$ & $\operatorname{meq~}^{-1}$ & $\%$ \\
\hline None & - & - & 0 \\
\hline FW 200 & 0.61 & 0.10 & 100 \\
\hline Carbolac 1 & 0.54 & 0.16 & 45.2 \\
\hline Neospectra II & 0.40 & 0.24 & 34.4 \\
\hline Philblack O & 0 & 0.02 & 11.5 \\
\hline
\end{tabular}

${ }^{\mathrm{a}}$ Carbon black, $0.50 \mathrm{~g} ; 3,1.0 \mathrm{~g} ; 150^{\circ} \mathrm{C} ; 5 \mathrm{~h}$.

sponsible for the initiation of the cationic ringopening transfer polymerization of SOEs at below $70^{\circ} \mathrm{C}$ are acidic sites, especially carboxyl groups. ${ }^{1}$

To clarify the functional groups responsible for the curing of SOE resins, the curing of 3 with various kinds of carbon black was carried out at $150^{\circ} \mathrm{C}$ for $5 \mathrm{~h}$ and the curing abilities of these carbon blacks were estimated in terms of functional group content. The results are summarized in Table IV.

It was found that the curing reaction of 3 proceeds in the presence of both channel black and furnace black. The gel fraction after the heating at $150^{\circ} \mathrm{C}$ for $5 \mathrm{~h}$ decreased in accordance with the content of carboxyl group on carbon black. This indicates that carboxyl groups on the surface of channel blacks play important roles in the curing of 3.

Furthermore, the curing reaction occurred even in the presence of furnace black Philblack $\mathrm{O}$, which contains no carboxyl groups, though Philblack $\mathrm{O}$ was unable to initiate the cationic polymerization of SOEs at $70^{\circ} \mathrm{C}$. This suggests that phenolic hydroxyl group on carbon black also has ability to cure SOE resins as well as phenol resin, although it is low.

Accordingly, the functional groups responsible for the curing of $\mathbf{3}$ are considered to be not only carboxyl groups but also phenolic hydroxyl groups on carbon black surface. 
Table V. Curing of 3 by treated carbon black

\begin{tabular}{|c|c|c|c|}
\hline \multirow{2}{*}{ Carbon black } & $\mathrm{COOH}$ & $\mathrm{OH}$ & Gel fraction ${ }^{\mathrm{a}}$ \\
\hline & meq $^{-1}$ & meq $\mathrm{g}^{-1}$ & $\%$ \\
\hline FW 200 & 0.61 & 0.10 & 100 \\
\hline KOH-FW 200 & Trace & Trace & 12.1 \\
\hline $\mathrm{CH}_{2} \mathrm{~N}_{2}-\mathrm{FW} 200$ & 0 & 0 & 4.5 \\
\hline $\mathrm{K}_{2} \mathrm{CO}_{3}-\mathrm{FW} 200$ & Trace & 0.10 & 17.9 \\
\hline Philblack O & 0 & 0.02 & 11.5 \\
\hline $\mathrm{HNO}_{3}$-Philblack O & 0.15 & 0.03 & 20.3 \\
\hline $\mathrm{H}_{2} \mathrm{O}_{2}$-Philblack O & 0 & 0.11 & 19.4 \\
\hline
\end{tabular}

a Carbon black, $0.50 \mathrm{~g} ; 3,1.0 \mathrm{~g} ; 150^{\circ} \mathrm{C} ; 5 \mathrm{~h}$.

\section{Curing of $\mathbf{3}$ by Modified Carbon Blacks}

To clarify the role of carboxyl and phenolic hydroxyl groups on carbon black surface in the curing of SOE resins, the curing of 3 by carbon black treated with potassium hydroxide, diazomethane, potassium bicarbonate, hydrogen peroxide, and nitric acid was compared with that of untreated one. The results are summarized in Table $\mathrm{V}$.

Carboxyl and phenolic hydroxyl groups are easily neutralized by treatment with an ethanol solution of potassium hydroxide. ${ }^{10}$ Furthermore, it has been found that carboxyl and phenolic hydroxyl groups are blocked by methylation with diazomethane. ${ }^{11}$ On the other hand, potassium bicarbonate reacts only with carboxyl groups.

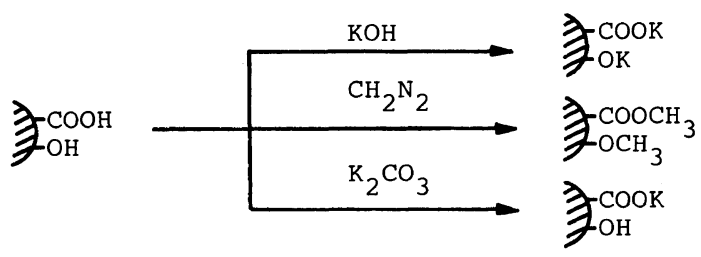

The results shown in Table $\mathrm{V}$ indicate that FW 200 lost the ability to cure 3 by treatment with potassium hydroxide or diazomethane.

Although the curing ability of FW 200 treated with potassium bicarbonate decreased in comparison with the untreated one, these modified carbon blacks somewhat kept the ability to cure 3 . The curing by potassium bicarbonate-treated carbon black is considered to be due to phenolic hydroxyl groups, which remain on carbon black surface after the treatment.

On the other hand, phenolic hydroxyl and carboxyl groups can be introduced on to the surface of furnace black Philblack $O$ by treatment with hydrogen peroxide ${ }^{12}$ and nitric acid, ${ }^{9}$ respectively. As shown in Table $\mathrm{V}$, the curing ability of Philblack $O$ increased by treatment with hydrogen peroxide or nitric acid.

Based on these results, it is concluded that the functional groups responsible for the curing of SOE resins are both carboxyl and phenolic hydroxyl groups on carbon black.

\section{Curing Mechanism of SOE Resins by Carbon Black}

It has been reported that when a Lewis acid is used as a curing agent, a catalytic amount of Lewis acid is enough to cure SOE resins because the curing proceeds through the ring-opening polymerization of $\mathrm{SOE}$ groups of the resin. ${ }^{2,6}$ But in the curing of SOE resin by use of acid anhydride, an equimolar amount of acid anhydride and SOE groups is required for the curing of the resin. Therefore, SOE resins are crosslinked through polyether ester linkage by use of a Lewis acid catalyst such as boron trifluoride etherate, while through polyester linkage by use of acid anhydride. ${ }^{2,6}$

As previously reported, carboxyl groups on carbon black act as catalysts of the ringopening transfer polymerization of SOE derivatives. ${ }^{1}$ Furthermore, the number of carboxyl groups on carbon black used for the curing of SOE resins much less than that of SOE groups of the resin.

Based on the above results, it is considered that the curing of SOE resins by carbon black occurs by the ring-opening transfer polymerization of SOE groups and that SOE resins are cured through polyether ester linkage as 


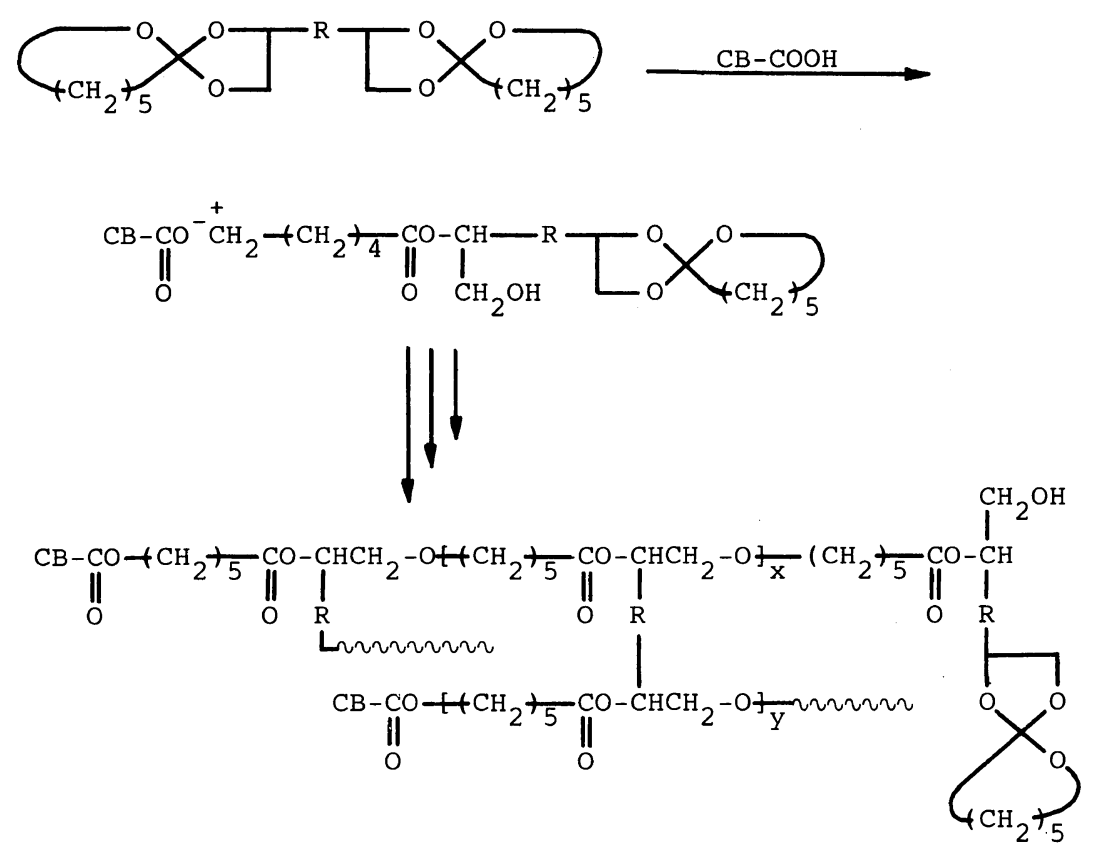

shown in the reaction scheme.

Acknowledgements. The authors thank Toagosei Chemical Ind. Co., Ltd. for providing the SOE resins.

\section{REFERENCES}

1. N. Tsubokawa, S. Ohshima, Y. Sone, and T. Endo, J. Polym. Sci., Polym. Chem. Ed., accepted for publication.

2. T. Endo and T. Ogasawara, Netsu Kokasei Jushi, 5, 98 (1984).

3. N. Tsubokawa, H. Sakamoto, and Y. Sone, Kobunshi Ronbunshu, 41, 597 (1984).
4. T. Endo and M. Okawara, Polym. Prepr., Jpn., 30, 192 (1981).

5. T. Endo, M. Okawara, and W. J. Bailey, J. Polym. Sci., Polym. Chem. Ed., 19, 1283 (1981).

6. T. Ogasawara, K. Mizutani, H. Kato, and T. Endo, Polym. Prepr., Jpn., 31, 11 (1982).

7. N. Tsubokawa, A. Funaki, Y. Hada, and Y. Sone, $J$. Polym. Sci., Polym. Chem. Ed., 20, 3297 (1982).

8. N. Tsubokawa, N. Takeda, and Y. Sone, Bull. Chem. Soc., Jpn., 55, 3541 (1982).

9. K. Ohkita, N. Tsubokawa, K. Sekine, and T. Yamada, Nippon Gomu Kyokaishi, 47, 40 (1974).

10. J. B. Donnet, Carbon, 20, 266 (1982).

11. M. L. Studebaker, E. W. D. Huffman, A. G. Wolfe, and L. G. Nabors, Ind. Eng. Chem., 48, 162 (1956).

12. K. Ohkita and H. Ohtani, Nippon Gomu Kyokaishi, 31, 14 (1957). 